\title{
The association of maize characteristics with resistance to Fusarium verticillioides and fumonisin accumulation in commercial maize cultivars
}

\author{
S. Links ${ }^{1,2 *}$, K. van Zyl ${ }^{1}$, A. Cassiem ${ }^{1}$, B.C. Flett ${ }^{3}$, A. Viljoen ${ }^{1}$ and L.J. Rose ${ }^{1}$ \\ ${ }^{1}$ Stellenbosch University, Faculty of AgriSciences, Stellenbosch, Matieland 7602, South Africa; ${ }^{2}$ Grain SA, Research and \\ Policy Centre, 457 Witherite Street, Willow Acres, Pretoria, 7600, South Africa; ${ }^{3}$ Agricultural Research Council, Grain \\ Crops, Potchefstroom, 2520, South Africa; stefan@grainsa.co.za
}

Received: 30 October 2019 / Accepted: 20 December 2019

(c) 2020 Wageningen Academic Publishers

OPEN ACCESS CC) (i) (요 RESEARCH ARTICLE

\begin{abstract}
Fusarium verticillioides is the primary fungus that causes Fusarium ear rot (FER) of maize. Infection results in reduced grain yield and quality due to moulding and the contamination of grain with toxic compounds namely fumonisins. Resistance to fungal infection and fumonisin accumulation in maize and maize grain is governed at different levels. In this study, the structural, physico-chemical and genetic basis of resistance to $F$. verticillioides was investigated in two, replicated field trials at Potchefstroom and Vaalharts in South Africa. Phenotypic data (silk length, husk coverage, pericarp thickness hundred-kernel mass and kernel hardness), physico-chemical data (kernel pH, moisture content, total nitrogen and carbon as well as phenolic acid content) and the expression of pathogenesis-related-5 gene (PR5) and peroxidase gene expression was evaluated in 15 commercial cultivars under artificially inoculated and natural infection conditions. The data were correlated to FER severity, fumonisin accumulation and fungal DNA (referred to as infection indicators). Disease development and fumonisin contamination in Vaalharts was significantly more than in Potchefstroom. There were no significant correlations $(r=\geq 0.60)$ between phenotypic characteristics and infection indicators. Kernel pH was the most important trait associated with disease development and was negatively correlated (between $r=-0.58$ and $r=-0.75$ ) to all infection indicators. PR5 gene expression had significant positive correlations $(r=0.69$ and $r=0.72)$ with the fungal and fumonisin levels, respectively. This study presents of the first data demonstrating the use of gene expression in identifying FER/fumonisin-resistant plant material and could aid breeders and growers in selecting resistant material more effectively.
\end{abstract}

Keywords: Fusarium verticillioides, fumonisin, infection indicator, gene expression

\section{Introduction}

Fusarium ear rot (FER) of maize is caused by Fusarium verticillioides (Saccardo) Nirenberg, Fusarium proliferatum (Matsushima) Nirenberg, Fusarium subglutinans (Saccardo) Nirenberg and Fusarium temperatum (Scauflaire and Munaut) (Schoeman et al., 2018). These are all mycotoxigenic pathogens that affect maize (Zea mays L.) at all stages of development (Foley, 1962; Munkvold, 2003a). Of the FER pathogens, $F$. verticillioides is considered to be the most important in Southern Africa (Boutigny et al., 2012; Schoeman et al., 2018).
The contamination of maize grain with $F$. verticillioides is a major constraint to maize production resulting in a reduction of yield and quality (Gerber et al., 2010; Presello et al., 2008). F. verticillioides causes rotting of maize kernels and produces a range of toxic secondary metabolites, called mycotoxins, of which fumonisins are the most important (Gelderblom et al., 1988). The ingestion of fumonisincontaminated maize cause health implications in humans and animals including oesophageal cancer in humans, leukoencephalomalacia in horses as well as liver and kidney damage in sheep (Kriek et al., 1981; Marasas et al., 1981, 2004). 
The success of the pathogen is largely attributed to the hemi-biotrophic nature that allows it to colonise plant tissue endophytically or later become a necrotroph (Bacon and Hinton, 1994; Bacon et al., 2008). From the anthesis period the kernel microenvironment favours the endophytic development of the pathogen, allowing it to proliferate without necessarily causing cell death (Wicklow et al., 2005). Induction of the necrotrophic phase, although not fully understood, is related to biotic and abiotic stress endured by the pathogen (Bacon and Hinton, 1994; Bacon et al., 2008). These stress factors can include other microorganisms competing for nutrients, plant cell $\mathrm{pH}$, water availability, plant drought or water logging (Bacon et al., 2001, 2008). Although fumonisins have been shown to accumulate during the endophytic phase, it is strongly associated with the necrotrophic phase (Bacon and Hinton, 1994; Bacon et al., 2008). Furthermore, the disease is also strongly driven by environmental conditions (Pérez-Brito et al., 2001; Rose et al., 2016). Warmer, dryer conditions, especially around silking, increase the rate of successful infection, the pathogen breeching host-defence mechanisms, and, therefore, increasing the likelihood of disease development and fumonisin accumulation down the line (Cao et al., 2014).

Management of FER/fumonisins is particularly challenging (Munkvold, 2003a). Successful practices for managing the disease are limited. Cultural practices are aimed at creating an environment that is less conducive for infection and disease development in the field (Munkvold, 2003b). Practices such as fertilisation methods, biocontrol agents, application of insecticides, tillage, crop rotation and adjusting planting and harvesting dates have been investigated (Flett et al., 1998; Mabuza et al., 2018; Munkvold, 2003b; Parsons and Munkvold, 2010; Pereira et al., 2007). Cultural practices are by large ineffective in controlling $F$. verticillioides in the field especially when environmental conditions are conducive for disease and mycotoxin development (Cao et al., 2014; Munkvold, 2003c). Plant resistance, therefore, presents the most feasible method to control FER and fumonisin accumulation (Maschietto et al., 2017; Munkvold, 2003b). The strong environmental effect and polygenic nature of resistance to F. verticillioides complicate breeding endeavours (Lanubile et al., 2017; Pérez-Brito et al., 2001). A number of factors are documented to contribute to FER/fumonisin-resistance within maize inbred lines such as phenotypic, physicochemical and genetic factors (Mesterházy et al., 2012; Picot et al., 2010). However, the relative importance of all these factors and how they correlate to each other are not well characterised.

Resistance in maize to $F$. verticillioides is mediated at different levels. Initially successful infection of maize kernels depends on the fungus crossing certain barriers. These include the length of maize silks, duration of silking, silk wetness and husk coverage (Maiorano et al., 2009; Parsons and Munkvold, 2010; Reid et al., 1992; Warfield and Davis, 1996). Susceptibility of maize has been documented to increase with shorter silks, faster silk senescence and incomplete husk coverage. The maize kernel has certain structural features that can contribute to resistance, i.e. the pericarp layer. Studies have shown that maize kernels with a thicker pericarp had lower fumonisin levels than ones with thinner pericarps (Sampietro et al., 2013). Additionally, the pericarp has different layers contributing to the overall hardness of the kernel (Fox and Manley, 2009). Furthermore, hardness can also be indicated by several other kernel factors such as the vitreous and starchy endosperm, size, weight and density (Guelpa et al., 2015). Tolerance to cracking of kernels indirectly contributes to resistance to pathogens by preventing wounds that can act as infection sites for F. verticillioides (Sampietro et al., 2013) and other mycotoxigenic fungi.

Following successful breech of structural barriers, F. verticillioides interacts with the kernel microenvironment where resistance to the fungus may be mediated at a physico-chemical level (Picot et al., 2010). Developing kernels initially has an alkaline $\mathrm{pH}$ and high moisture content (Warfield and Gilchrist, 1999). Reports suggest that the fungus has mechanisms in place, such as the PAC1 protein, to allow fungal growth under these conditions (Flaherty et al., 2003). Fumonisin production, however, is reportedly suppressed at alkaline conditions (Shim et al., 2003). As kernel development progresses, nitrogen and free water becomes more limiting and kernel $\mathrm{pH}$ becomes more acidic (pH 3.0-4.0) (Keller et al., 1997). This is correlated with an increase in fumonisin production (Jurado et al., 2008; Keller et al., 1997; Shim et al., 2003). Furthermore, maize kernels inoculated with $F$. verticillioides has been shown to have a lower $\mathrm{pH}$ than water inoculated kernels (Van Zyl, 2015). Therefore, maize genotypes that are predisposed to factors such as higher kernel $\mathrm{pH}$ or nitrogen content during kernel development could also indirectly contribute to resistance to FER (Marín et al., 2004). Phenolic compounds in maize kernels may play an active role in resistance to fungal pathogens (SalinasMoreno et al., 2017; Zabka and Pavela, 2013). Phenolic compounds are secondary metabolites produced by plants both constitutively and in response to external stimuli (Ponts et al., 2011). They limit the growth of $F$. verticillioides as well as break down fungal cell membranes (Boutigny et al., 2008; Ponts et al., 2011). Furthermore, they have been shown to detoxify fumonisins in vitro (Beekrum et al., 2003; Ferrochio et al., 2013).

The molecular basis of resistance to FER and fumonisin accumulation has been extensively investigated in maize (Lanubile et al., 2010, 2014, 2017; Maschietto et al., 2016). This includes the induction of pathogenesis-related $(P R)$ genes following pathogen infection (Breen et al., 2017). 
Effective at low concentrations, $P R$ genes are expressed in all plant-pathogen interactions in an attempt to inhibit pathogen colonisation (Maschietto et al., 2016; Sinha et al., 2014). Lanubile et al. (2010) reported that PR1, PR5, PRm3 and $P R m 6$ were found in a maize inbred line susceptible to $F$. verticillioides when compared to a tolerant line prior to inoculation, but that their expression was increased 48 hours after inoculation (Lanubile et al., 2010). Genes that protect maize kernels from oxidative stress, i.e. peroxidase have also been associated with resistance in maize to F. verticillioides (Lanubile et al., 2017; Maschietto et al., 2016).

There has been much progress in terms of understanding the maize - F. verticillioides pathosystem and how individual characteristics relate to resistance in maize inbred lines. However, there is limited understanding on how these characteristics relate to each other or how the collective knowledge can be applied to identify resistant genotypes. The purpose of this study was to investigate host resistance traits at the structural, physico-chemical and genetic level of uncharacterised commercial maize cultivars resistant or susceptible to FER and fumonisin accumulation. Information obtained in this study would help breeders and producers to select FER/fumonisinresistant material more efficiently.

\section{Materials and methods}

\section{Plant material and artificial inoculation}

Fifteen commercial cultivars, planted during the 2016/17 season, were randomly selected for this study (Table 1). The cultivars were planted in two localities; Potchefstroom (grid ref.: $26730 \mathrm{~S}, 27070 \mathrm{E}$; altitude, 1,349 m) and Vaalharts (grid ref.: $27950 \mathrm{~S}, 24830 \mathrm{E}$; altitude, 1,180 m) representing dryland and irrigation production, respectively. Each cultivar was planted in three field plots in a randomised complete block design at each locality. Field plots consisted of two 10-m rows, $1 \mathrm{~m}$ spacing between rows and maize kernels were planted with an intra-row spacing of $0.3 \mathrm{~m}$.

The primary maize ears were inoculated at anthesis with the highly pathogenic, highly virulent and high fumonisin producing F. verticillioides isolate MRC 826 (Programme on Mycotoxins and Experimental Carcinogenesis, Medical Research Council (PROMEC-MRC), Tygerberg, South Africa). Silk channel inoculation was performed (Reid et al., 1999) using a spore concentration of $2 \times 10^{6}$ spores $/ \mathrm{ml}$ (Booth, 1971). The control (further referred to as naturally infected) maize ears were inoculated with $1 \mathrm{ml}$ sterile deionised $\mathrm{H}_{2} \mathrm{O}$ in each plot.
Table 1. Fifteen commercial maize cultivars evaluated at Potchefstroom and Vaalharts during the $2016 / 17$ season.

$\begin{array}{lll}\text { Cultivar number } & \text { Grain colour } & \text { GM/non-GM }{ }^{1} \\ 1 & \text { yellow } & \text { GM } \\ 2 & \text { yellow } & \text { GM } \\ 3 & \text { yellow } & \text { Non-GM } \\ 4 & \text { yellow } & \text { GM } \\ 5 & \text { yellow } & \text { Non-GM } \\ 6 & \text { yellow } & \text { GM } \\ 7 & \text { yellow } & \text { Non-GM } \\ 8 & \text { white } & \text { GM } \\ 9 & \text { white } & \text { GM } \\ 10 & \text { white } & \text { GM } \\ 11 & \text { white } & \text { GM } \\ 12 & \text { white } & \text { Non-GM } \\ 13 & \text { white } & \text { Non-GM } \\ 14 & \text { white } & \text { GM } \\ 15 & \text { white } & \text { Non-GM }\end{array}$

${ }^{1} \mathrm{GM}$ = genetically modified; Non-GM = non-genetically modified.

\section{Grain processing}

Maize plants were allowed to dry naturally infield for 4 to 6 weeks before being manually harvested (primary ear only) per row. The primary ear of each cultivar was pooled per row with fungal- and water-inoculated ears kept separately. Ears were threshed, and the grain was pooled. A $250 \mathrm{~g}$ sample of kernels per field replicate (Janse van Rensburg et al., 2011) was milled and stored at $-20^{\circ} \mathrm{C}$, while an additional $50 \mathrm{~g}$ was milled and stored at $-80^{\circ} \mathrm{C}$ for further analyses.

\section{Structural trait assessments}

The silks of 25 primary ears per cultivar were measured at anthesis for each field plot. Measurements were taken from the point of silk emergence from the husk leaves to the tip of the silks (Table 2). Husk coverage was visually scored as open or closed depending on the visibility of kernels, at anthesis and again at harvest (Table 2).

Kernel hardness was assessed using two methods: hundredkernel mass (HKM) (Guelpa et al., 2015) and near-infrared (NIR) spectroscopy (Downey et al., 1986) (Table 2). NIR spectroscopy was performed using the NIRFlex N-500 Frontier Transformed (FT-NIR) spectrophotometer (BÜCHI Labortechnik GmbH, Flawil, Switzerland) and NIR LabWare version 3.0 software (BÜCHI Labortechnik $\mathrm{GmbH}$ ) and evaluated in the diffuse reflectance mode. Samples were subjected to NIR light at a resolution of 32 $\mathrm{cm}^{-1}$ from 1,100 to $2,500 \mathrm{~nm}$. Absorbance measurements 
Table 2. Structural, physico-chemical and genetic factors measured.

\begin{tabular}{|c|c|c|}
\hline Structural & Physico-chemical & Gene expression \\
\hline $\begin{array}{l}\text { Silk length } \\
\text { Husk coverage (at anthesis } \\
\text { and at harvest) } \\
100-\text { Kernel mass } \\
\text { Kernel hardness (NIR) }{ }^{1} \\
\text { Pericarp thickness }\end{array}$ & $\begin{array}{l}\text { moisture content } \\
\mathrm{pH} \\
\text { phenolic acids (free, } \\
\text { bound and total) } \\
\text { carbon to nitrogen } \\
\text { ratio }\end{array}$ & $\begin{array}{l}\text { PR5 } \\
\text { peroxidase }\end{array}$ \\
\hline
\end{tabular}

were calculated by the NIR LabWare software based on the light reflected. Absorbance measurements $(1 / R)$ at 2,230 nm were used in a formula proposed by Downey et al. (1986) to obtain index values for hardness as follows, hardness = $\alpha+b(\log 1 / R)$, where $\alpha=-40$ and $b=100$. NIR spectroscopy was done for whole-kernel and flour samples.

The thickness of the kernel pericarp was measured using the ZEISS Stemi 508 Greenough Stereo Microscope (Carl Zeiss AG, Oberkochen, Germany) and visialised with the Axiocam ERc 5s camera (Carl Zeiss AG) (Table 2).

\section{Physico-chemical properties assessments}

The moisture content of maize grain was measured directly after harvest using the Draminkski TwistGrain moisture meter (Draminski Electronics, Olsztyn, Poland). The pH of maize grain was measured using the Jenway $3510 \mathrm{pH}$ meter (Bibby Scientific Limited, Stone, UK). The $\mathrm{pH}$ was assessed by mixing $500 \mathrm{mg}$ of finely milled flour with $5 \mathrm{ml}$ of sterile deionised $\mathrm{H}_{2} \mathrm{O}$ (Table 2).

The total soluble nitrogen and carbon in kernels was assessed using the TruSpec ${ }^{\circledR}$ Micro (LECO Corporation, St Joseph, MI, USA) at the Central Analytical Facility (CAF) at Stellenbosch University. Carbon and nitrogen content were assessed by Vario EL Cube elemental analysis.

Total phenolic acids were extracted as described by Cassiem (2018) by first extracting the free phenolic acids followed by the ester-bound phenolic acids. The quantification procedure employed an external standard dilution series using purified commercial products trans-ferulic, caffeic, $\rho$-coumaric, sinapic and $\rho$-hydroxybenzoic acids (SigmaAldrich, St. Louis, MO, USA). The standard curve consisted of a 10-point dilution series ranging from $0.0125-200 \mathrm{mg} /$ kg. Quantification was performed at CAF, Stellenbosch University, using a Synapt G2 quadruple time of flight (Q-TOF) mass spectrometer (Waters, Milford, MA, USA) with a chromatograph of Waters Ultra pressure liquid and a photo-diode array detection. Separation was accomplished using the High Strength Silica technology T3 operated in a negative electrospray ionisation mode (Waters) (Table 2).

\section{Gene expression of defence-related genes}

Total RNA was isolated as described by Wang et al. (2011). Flour, stored at $-80^{\circ} \mathrm{C}(0.2 \mathrm{~g})$ was used for RNA isolation using TRIS- $\mathrm{HCl}$ (pH 9.0) (Merck, Darmstadt, Germany) and TRIzol Reagent (Sigma-Aldrich). RNA was treated with RNase-free DNase set (QIAGEN, Hilden Germany) according to the manufacturer's recommendations and the RNA concentration determined using a ND-1000 NanoDrop Spectrophotometer (Inqaba Biotechnical Industries (Pty) Ltd, Pretoria, South Africa).

Complementary DNA (cDNA) was synthesised using the iScript cDNA synthesis kit (Bio-Rad Laboratories, Hercules, CA, USA) according to the manufacturer's protocol. Reverse transcription quantitative PCR (RT-qPCR) was performed to quantify the relative expression of peroxidase and PR5 in the fungus-inoculated and water-inoculated kernels while the elongation factor $(E F)-1 \alpha$ (Nicolaisen et al., 2009) was used as reference gene. Validation experiments were performed to ensure that the efficiencies of the target genes and reference gene amplifications were equal (Bustin et al., 2009). The RT-qPCR reactions were carried out on the CFX96 $6^{\text {mix }}$ Real-Time system (Bio-Rad Laboratories) according to the method described by Lanubile et al. (2010). A melt curve analysis ranging from $60-95^{\circ} \mathrm{C}$ was included in each run to ensure amplicon specificity. Cultivar field replications were pooled, and three technical replicates were performed for each cultivar. Template-free samples were included in each run. The relative expression of the defencerelated genes was calculated for the fungus-inoculated and naturally infected samples using the $2^{-\Delta \Delta C t}$ method (Livak and Schmittgen, 2001), where $\Delta \mathrm{C}_{\mathrm{t}}$ is the threshold cycle value difference between the target and reference gene of each reaction. The standard deviation (SD) of the $C_{t}$ values between replicates was less than $5 \%$ (Table 2).

\section{Climate data}

Supplemental irrigation was supplied as needed at both localities. In addition, the climatic data is given for the production season (December 2016 - August 2017). Potchefstroom had a minimum of $-4.1^{\circ} \mathrm{C}$ and a maximum temperature of $36.5^{\circ} \mathrm{C}$. During this period the accumulated rainfall amounted to $439.7 \mathrm{~mm}$, relative humidity ranged between 7.7 and $98.1 \%$ and the total heat units were 1,477. In Vaalharts, temperatures ranged between -4.7 and $43.4^{\circ} \mathrm{C}$, rainfall totalled $365.8 \mathrm{~mm}$, relative humidity ranged between 5.2 and $96.7 \%$ and there was a total of 2,260 heat units. 


\section{Infection indicators}

At harvest, the trials were assessed for visual disease severity. Severity assessments were performed on a continuous scale from 1-10, with 1 being no visual symptoms and 10 being completely colonised. The primary ears of 15 plants were assessed for each field plot and expressed as a percentage.

Total fumonisins were extracted from maize flour using a methanol/water (70:30, v/v) extraction buffer according to Rose et al. (2016). Fumonisin extracts were submitted to CAF, Stellenbosch University, for LC-MS/MS. Fumonisin standards $\mathrm{FB}_{1}, \mathrm{FB}_{2}$ and $\mathrm{FB}_{3}$ was prepared as described by Small et al. (2012). A 6-point standard curve was set up ranging from 0.05 to $20.16 \mathrm{mg} / \mathrm{kg}$ for $\mathrm{FB}_{1}$ and $\mathrm{FB}_{2}$ and 0.005 to $2.08 \mathrm{mg} / \mathrm{kg}$ for $\mathrm{FB}_{3}$.

Genomic DNA of grain samples and $F$. verticillioides MRC 826 mycelia was extracted according to Boutigny et al. (2012). Quantitative (q)PCR was performed to quantify the amount of $F$. verticillioides target DNA in the maize kernels as described by Boutigny et al. (2012). The melting temperature $\left(\mathrm{T}_{\mathrm{m}}\right)$ of the amplicons was assessed to confirm analytical specificity. The $\mathrm{SD}$ of the $\mathrm{C}_{t}$ values for a sample was less than $5 \%$. Standard DNA (16 times dilution) was included in the qPCR assay and analysed in triplicate. Using the matrix specific standard curves, the $C_{t}$ values of sampled evaluated were transformed into DNA concentrations using the Rotor-Gene ${ }^{\mathrm{mi}}$ 2.0.2.4 software.

\section{Data analysis}

One-way analysis of variance (ANOVA) was performed to assess the response of cultivars for the parameters evaluated in this study. Where variation deviated from normality, log- transformation was performed to improve homogeneity. ANOVA revealed significant differences between localities and, therefore, ANOVA was subsequently performed per locality (Results not shown). Pearson's correlation was performed for each locality to determine correlations between resistance characteristics and infection indicators. Multifactor analysis (MFA) was assessed for all trials to determine whether significant correlations exist between plant traits and the infection indicators. For the MFA, individual parameters were placed in groups as follows: structural characteristics, physico-chemical properties and genetic responses and compared to the group of infection indicators. Partial least squares regression was performed to test correlations between individual characteristics and the group of infection indicators. Within these multivariate analyses, both the log-transformed and non-log-transformed data was included.

\section{Results}

No gene expression analyses were performed on cultivars evaluated at Potchefstroom due to the low levels of infection indicators. Gene expression could not be obtained for cultivar 15 (Vaalharts). Relative peroxidase expression (fold change) in the fungal-inoculated grain was higher in cultivar 14 (0.297-fold) than any other cultivar evaluated (Figure 1). Alternatively, cultivars 1, 3, 6 (0.034-fold) and 4 ( 0.043 -fold) had the lowest expression of peroxidase. In the water-inoculated grain, cultivar 14 (1.182-fold) still had the greatest expression (Figure 1). Cultivars 1 (0.059-fold) and 13 (0.062-fold) had the lowest relative expression. In terms of the fungal-inoculated grain, expression of PR5 was highest in cultivar 5 (0.143-fold), not differing significantly from cultivar 14 (0.137-fold) (Figure 2). In the water-inoculated grain, cultivars 11 (0.057-fold) and

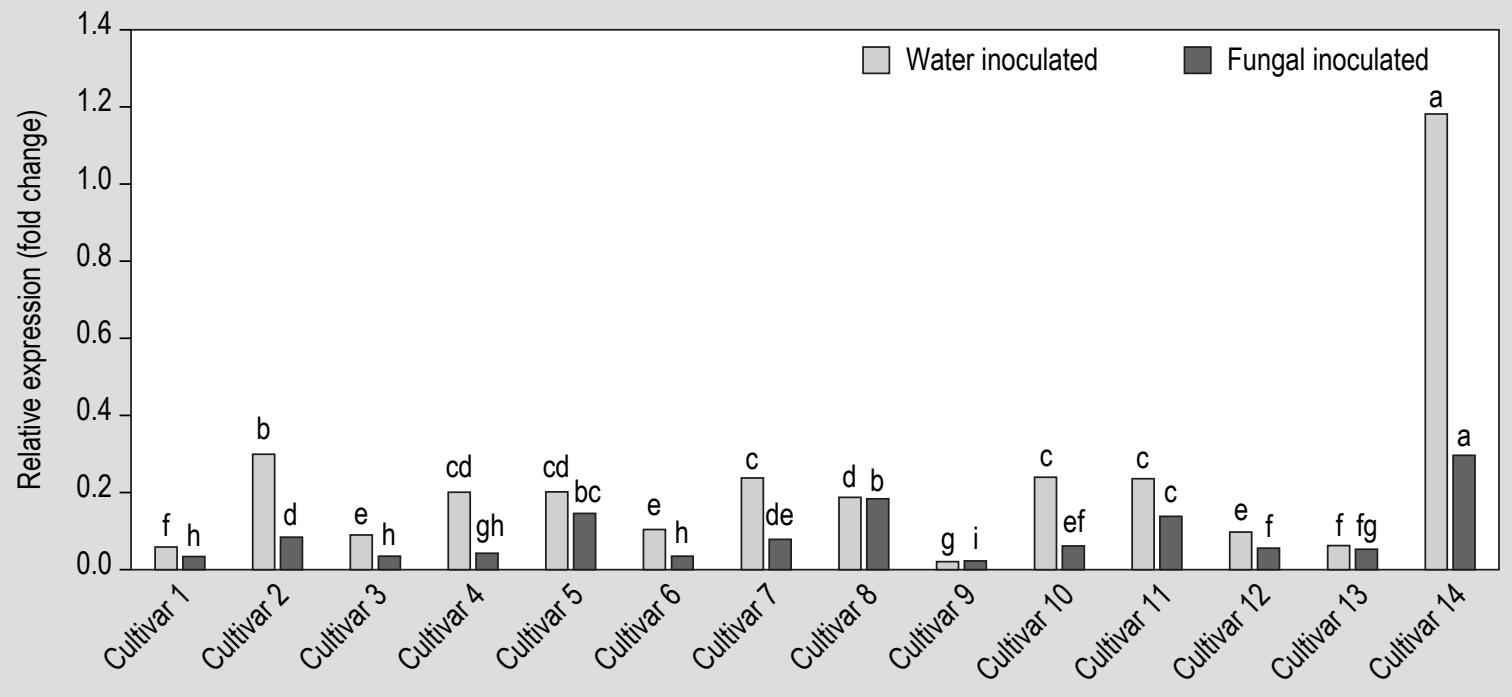

Figure 1. Expression of peroxidase gene commercial maize cultivars grown in Vaalharts. Bars marked with the same superscript do not differ significantly $(P>0.05)$. 


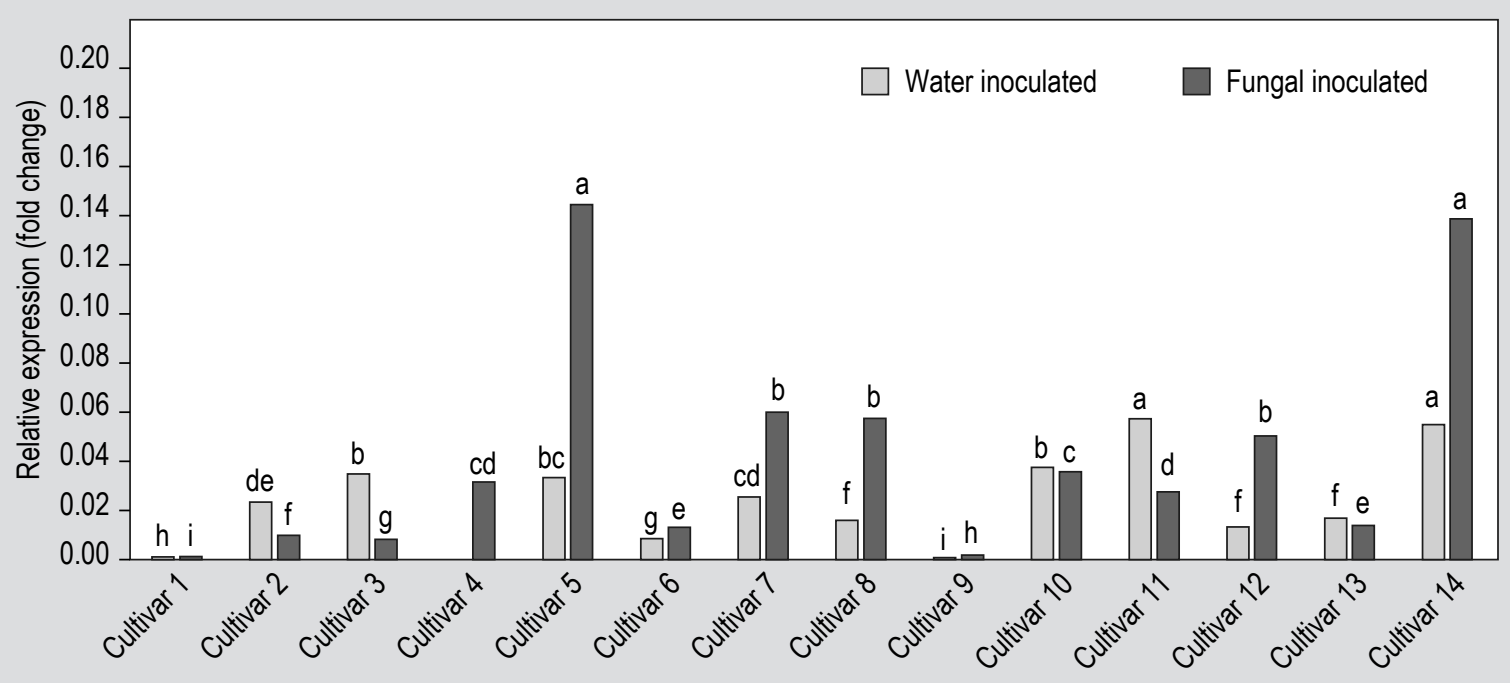

Figure 2. Expression of pathogenesis-related 5 (PR5) relative in commercial maize cultivars grown in Vaalharts. Bars marked with the same superscript do not differ significantly $(P>0.05)$.

14 (0.055-fold) had the lowest expression. There was no detectable expression of $P R 5$ in the water-inoculated grain of cultivar 4 , other than that, cultivar 9 (0.001-fold) had the lowest expression (Figure 2).

\section{Pearson's correlations between phenotypic and physico- chemical characteristics with infection indicators}

Only correlations with a Pearson's correlation coefficient (r) of $\geq 0.60$ were considered as noteworthy correlations. In Potchefstroom, there were significant positive correlations between fumonisin levels and fungal target DNA levels with both inoculated $(r=0.70)$ and naturally infected $(r=0.74)$ samples (Table 3). In Vaalharts, the kernel $\mathrm{pH}$ had an inverse correlation with infection indicators including visual disease severity $(r=-0.73)$, total fumonisins $(r=-0.72)$ and fungal target DNA ( $\mathrm{r}=-0.75)$ of inoculated grain (Table 4). The expression of the PR5 gene in inoculated samples had significant positive correlations with different infection indicators, including total fumonisins of naturally infected $(\mathrm{r}=0.72)$ and inoculated $(\mathrm{r}=0.71)$ grain samples as well as with the fungal target DNA levels of the inoculated grain $(r=0.69)$. Infection indicator, FER severity, had significant correlations with other infection indicators including total fumonisins of inoculated samples $(r=0.69)$. Fumonisins and fungal target DNA levels of inoculated grain $(r=0.94)$ had a strong positive correlation (Table 4). A similar trend was seen in the naturally infected samples, where

Table 3. Pearson's correlation matrix of physico-chemical properties with infection indicators of maize cultivars evaluated in Potchefstroom during the 2016/17 season. ${ }^{1,2}$

\begin{tabular}{|c|c|c|c|c|c|}
\hline & FER severity & Total fumonisins (N) & Total fumonisins (I) & Fungal target DNA (I) & Fungal target DNA (N) \\
\hline $\mathrm{pH}$ & $-0.49^{*}$ & -0.10 & -0.16 & -0.09 & -0.11 \\
\hline Phenolic acids (free) & $0.32^{*}$ & -0.17 & 0.00 & 0.28 & 0.06 \\
\hline Phenolic acids (total) & $0.33^{*}$ & -0.25 & -0.08 & 0.23 & 0.03 \\
\hline Total nitrogen & $0.33^{*}$ & 0.11 & $-0.35^{*}$ & $-0.31^{*}$ & 0.05 \\
\hline Total carbon & 0.17 & -0.11 & -0.05 & -0.03 & -0.06 \\
\hline $\mathrm{C} / \mathrm{N}$ & 0.33 & -0.12 & $0.41^{*}$ & $0.35^{*}$ & -0.02 \\
\hline Total fumonisins (N) & 0.23 & 1.00 & 0.24 & 0.11 & $0.70^{*}$ \\
\hline Total fumonisins (I) & 0.10 & 0.24 & 1.00 & $0.75^{\star}$ & -0.10 \\
\hline Fungal target DNA (I) & 0.23 & 0.11 & $0.75^{*}$ & 1.00 & -0.12 \\
\hline Fungal target DNA (N) & 0.05 & $0.70^{*}$ & -0.10 & -0.12 & 1.00 \\
\hline
\end{tabular}


Table 4. Pearson's correlation matrix of structural characteristics, physico-chemical properties and genetic responses with infection indicators of maize cultivars evaluated in Vaalharts during the 2016/17 season. ${ }^{1,2}$

\begin{tabular}{|c|c|c|c|c|c|}
\hline & FER severity & Total fumonisins (N) & Total fumonisins (I) & Fungal target DNA (I) & Fungal target DNA (N) \\
\hline $\mathrm{pH}$ & $-0.73^{*}$ & $-0.69^{*}$ & $-0.72^{*}$ & $-0.75^{\star}$ & $-0.58^{*}$ \\
\hline Phenolic acids (bound) & $0.32^{*}$ & 0.16 & $0.30^{*}$ & 0.24 & 0.03 \\
\hline Total nitrogen & $0.34^{*}$ & 0.29 & $0.30^{*}$ & $0.32^{*}$ & 0.25 \\
\hline Total carbon & 0.01 & 0.05 & 0.13 & 0.11 & 0.00 \\
\hline $\mathrm{C} / \mathrm{N}$ & $-0.37^{*}$ & $-0.41^{*}$ & $-0.31^{*}$ & $-0.36^{*}$ & $-0.36^{*}$ \\
\hline Relative peroxidase expression (N) & 0.10 & $0.37^{*}$ & 0.28 & 0.24 & $0.35^{*}$ \\
\hline Relative peroxidase expression (I) & 0.18 & $0.39^{*}$ & $0.40^{*}$ & $0.36^{*}$ & $0.34^{*}$ \\
\hline Relative PR5 expression (N) & $0.46^{*}$ & $0.59^{*}$ & $0.59^{*}$ & $0.53^{*}$ & $0.60^{*}$ \\
\hline Relative PR5 expression (I) & $0.47^{*}$ & $0.72^{*}$ & $0.71^{*}$ & $0.69^{*}$ & $0.62^{*}$ \\
\hline FER severity & 1.00 & $0.58^{*}$ & $0.69^{*}$ & $0.63^{*}$ & $0.55^{*}$ \\
\hline Total fumonisins (N) & $0.58^{*}$ & 1.00 & $0.71^{*}$ & $0.75^{\star}$ & $0.89^{*}$ \\
\hline Total fumonisins (I) & $0.69^{*}$ & $0.71^{*}$ & 1.00 & $0.94^{*}$ & $0.65^{*}$ \\
\hline Fungal target DNA (I) & $0.63^{*}$ & $0.75^{*}$ & $0.94^{*}$ & 1.00 & $0.67^{*}$ \\
\hline Fungal target DNA (N) & $0.55^{*}$ & $0.89^{*}$ & $0.65^{*}$ & $0.67^{*}$ & 1.00 \\
\hline
\end{tabular}

fumonisins and fungal target DNA levels $(r=0.89)$ had a strong positive correlation. The fumonisin levels measured in naturally infected grain was also significantly correlated to fumonisin levels measured in inoculated grain $(\mathrm{r}=0.71)$ as well as fungal target DNA levels $(\mathrm{r}=0.75)$ of inoculated grain (Table 4).

\section{Multivariate analysis}

Principle component biplot of cultivars response supported ANOVA analysis with the first principal component (F1) separating most of the variables based on locality (Figure 3). The biplot explained $57.1 \%$ of the variation, with F1

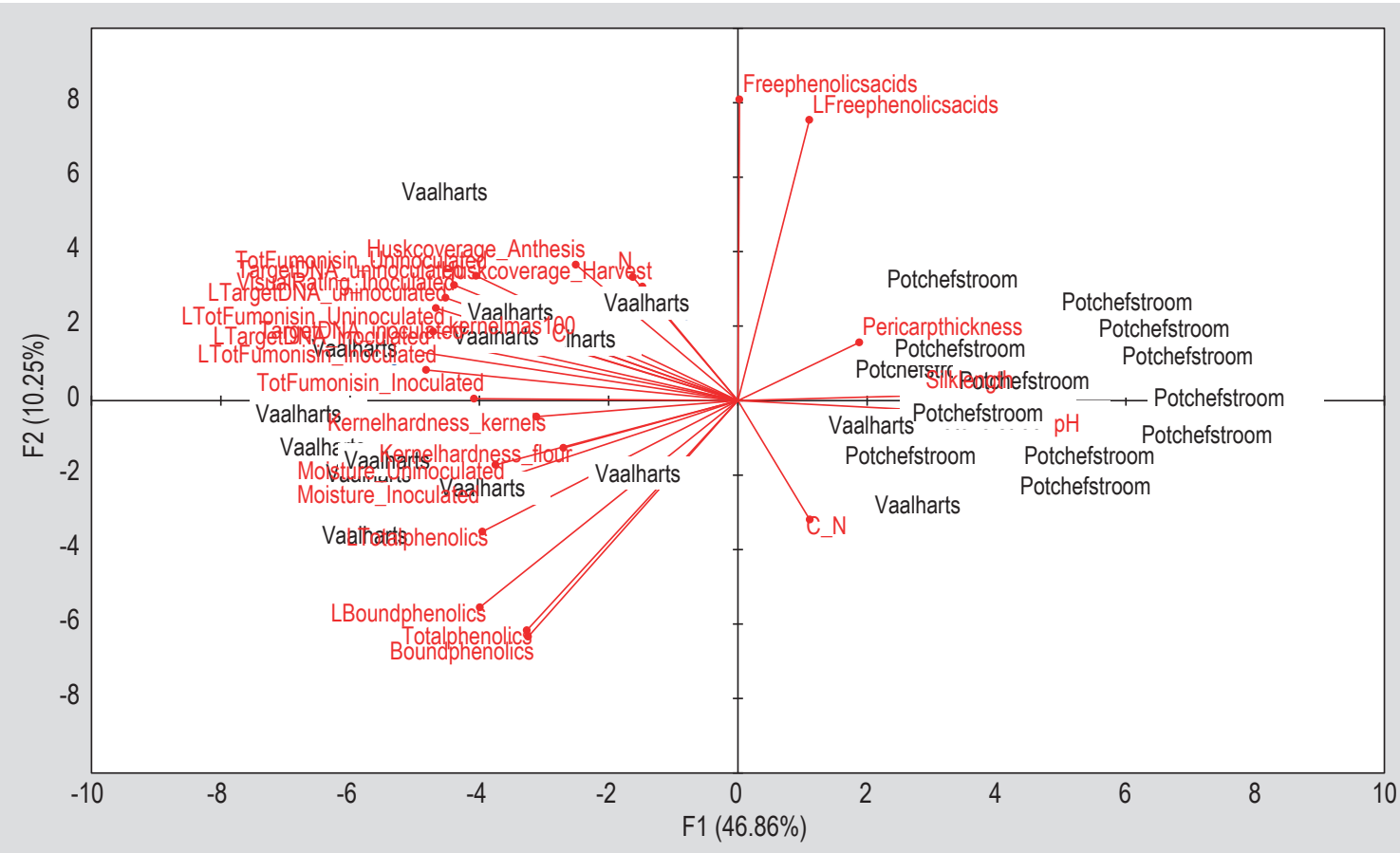

Figure 3. Principle component biplot of commercial maize cultivars showing all structural, physico-chemical and genetic characteristics evaluated. 
responsible for $46.9 \%$ and F2 accounting for $10.3 \%$ of the variation observed. Most variables made a significant contribution to variation on F1, including infection indicators, genetic variables as well as $\mathrm{pH}$ and moisture content. Based on F1, most variables were positively associated with samples in Vaalharts and negatively associated with samples in Potchefstroom, with the exception of pericarp thickness, silk length, kernel $\mathrm{pH}$ and $\mathrm{C} / \mathrm{N}$. Only free phenolic acids significantly separated samples on F2 (Figure 3). MFA was only performed for Vaalharts. even though most of the variables evaluated in this study were associated with each other, no correlations between the different groups of variables (levels of resistance), including structural characteristics (squared Pearson's correlation coefficient $(R V)=0.08)$, physicochemical properties $(R V=0.21)$ or genetic responses $(\mathrm{RV}=0.30)$, with infection indicators could be determined
(Figure 4). The biplot explained $41.9 \%$ of the variation observed where $24.1 \%$ of the variation was explained by F1 and $17.8 \%$ explained by F2. Although most of the variables were positively associated, there were no significant correlations between the groups of factors. The group of infection indicators were, however, strongly associated with each other (Figure 4). Since MFA could not determine a clear correlation of the groups of variables, partial least squares regression analysis was performed for the group of infection indicators vs individual resistance characteristics (Figure 5). Certain characteristics correlated with infection indicators namely physico-chemical properties including $\mathrm{pH}$ (Variable importance of the projection $(\mathrm{VIP})=2.3$ ), $\mathrm{N}$ $(\mathrm{VIP}=1.2)$ and $\mathrm{C} / \mathrm{N}(\mathrm{VIP}=1.3)$, genetic response of $P R 5$ in inoculated grain ( $\mathrm{VIP}=2.2), P R 5$ expression of the naturally infected grain $(\mathrm{VIP}=1.9)$ as well as peroxidase activity in the inoculated grain (VIP=1.2) (Figure 5).

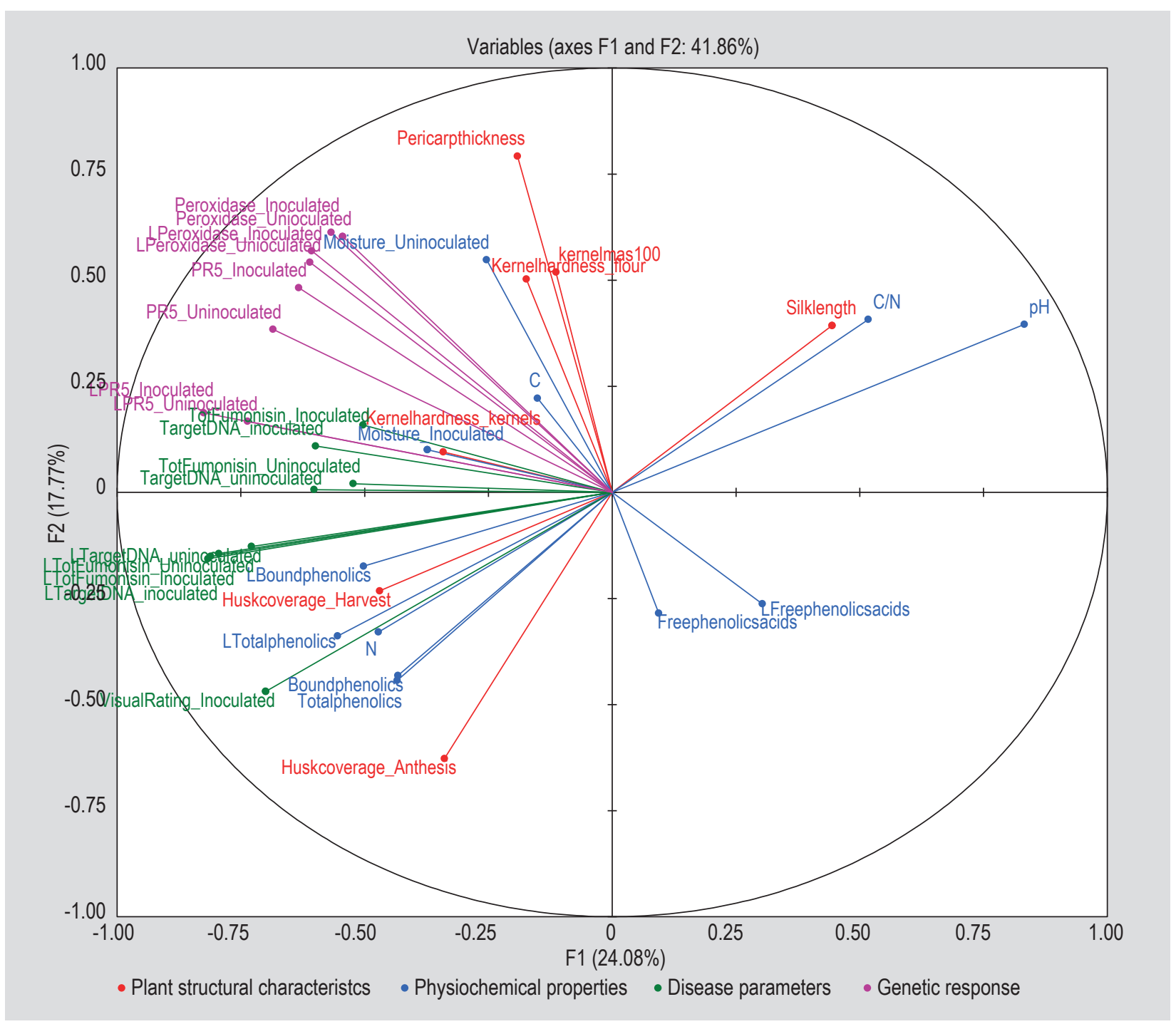

Figure 4. Multifactor biplot of commercial cultivars in Vaalharts showing correlations between the different levels of resistance. 


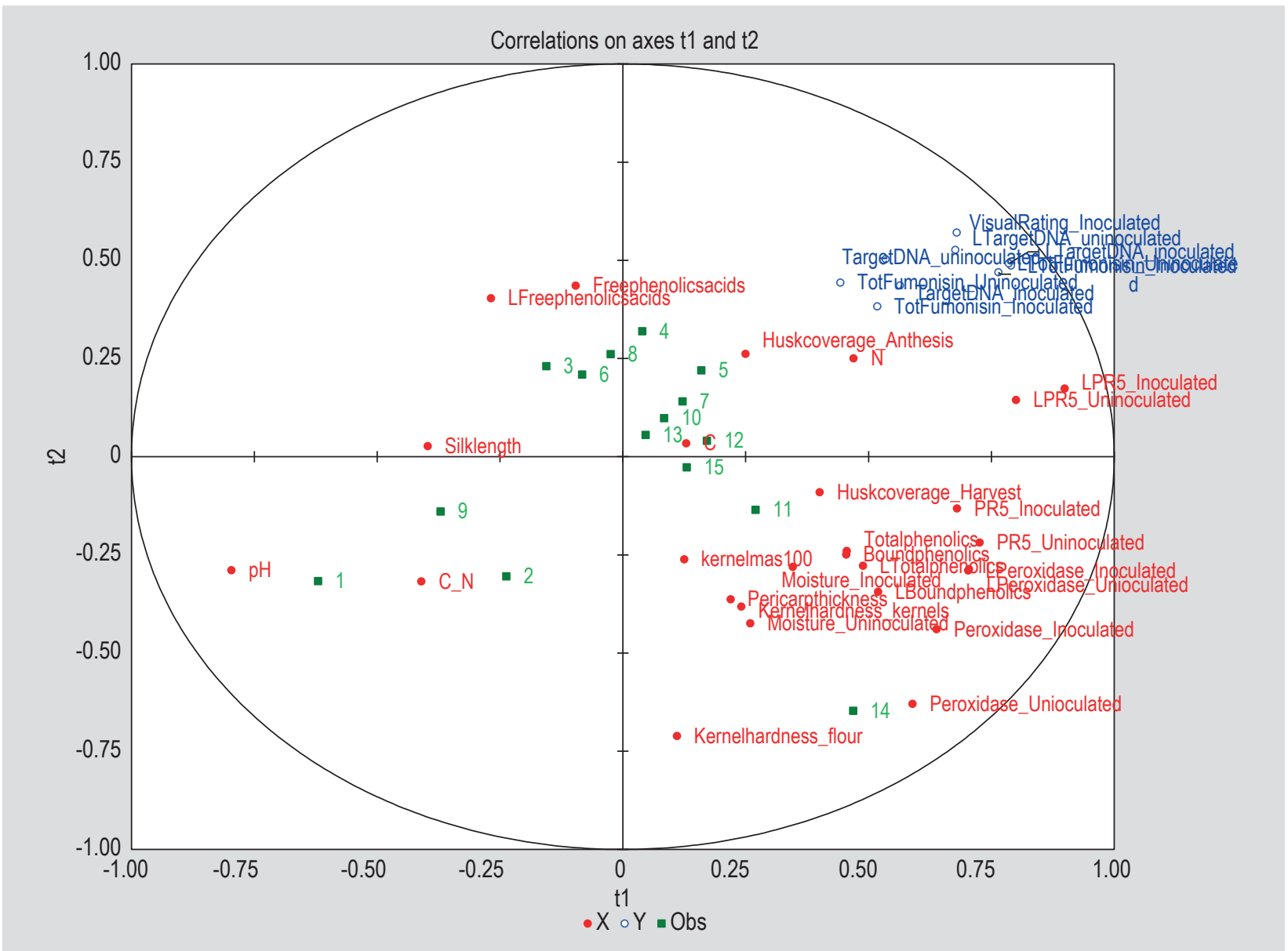

Figure 5. Partial least squares biplot of commercial cultivars in Vaalharts indicating correlations of infection indicators with individual phenotypic, physico-chemical and genetic characteristics.

\section{Discussion}

Structural, physico-chemical and genetic characteristics of maize, potentially contributing to resistance to $F$. verticillioides, were explored in uncharacterised commercial cultivars. This study, serving as preliminary data, is the first to report on the relationship between factors, representing different levels of resistance, to FER and fumonisin accumulation.

Resistance to $F$. verticillioides by maize is multifactorial; however, no association between structural, physicochemical and genetic characteristics, representing different levels of resistance, and traditional infection indicators could be determined. Infection indicators including field evaluation for resistance, fumonisin and/or fungal quantification is the gold standard for determining plant response to $F$. verticillioides/fumonisins, however, the process is time consuming and labour intensive (Sampietro et al., 2010). Therefore, the association of maize characteristics, that can be assessed much earlier and faster, would facilitate more efficient identification of resistant material. Although the different levels of resistance did not correlate with infection indicators, some individual characteristics strongly correlated with these.

Defence-related genes were good indicators of potential resistance to $F$. verticillioides, in this study. The association of genes, including PR5 and peroxidase, and infection indicators was observed in Vaalharts. This suggests that the genetic potential of the genotype is a key component of resistance to FER and fumonisin accumulation. A positive correlation was found between peroxidase and fungal- and fumonisin-contamination. This demonstrates the ability of the fungus to influence the expression of defence-related genes and the potential of the plant to defend itself.

Defence-related gene expression was low at harvest in the resistant cultivars. Resistant cultivars 1 and 9 had lower peroxidase expression levels than the moderately susceptible cultivar 14. Similarly, cultivars 1 and 9 also had lower PR5 expression levels than susceptible cultivars 5,10 and the moderately susceptible cultivar 14 . These results suggest that resistant genotypes could have other genes that contribute to its observed resistance. Moreover, low gene expression at harvest potentially indicates that $F$. 
verticillioides is no longer perceived as a threat, due to low levels, and thus the plant does not require the expression of defence-related genes at this point. Defence-related genes have been shown to be associated with resistance to FER and fumonisin accumulation in maize (Lanubile et al., 2010, 2017; Maschietto et al., 2016; Van Zyl, 2018). Most of these studies focused on gene expression at initial stages of kernel development; however, the results of this study are supported by the findings of Van Zyl (2018) who determined the genetic response of maize inbred lines as late as 52 days after inoculation with $F$. verticillioides. It is important to note that considering the difference between the water-inoculated and fungal-inoculated expression of peroxidase it may demonstrate, in cultivar 14, an example of the fungus' ability to modulate gene expression to ensure successful infection (Lanubile et al., 2017). This is the first study that quantified defence-related gene expression, amongst other factors, following harvest and confirms that greater expression of defence related genes in susceptible genotypes after $F$. verticillioides infection.

Physico-chemical factors including kernel $\mathrm{pH}$ and the carbon:nitrogen ratio $(\mathrm{C} / \mathrm{N})$ strongly influenced the suitability of the kernel microenvironment for fungal infection and fumonisin accumulation. The kernel $\mathrm{pH}$ had a significant inverse relationship with infection indicators. Previous studies, such as Flaherty et al. (2003) revealed that acidic conditions were associated with fumonisin accumulation in vitro. The kernel $\mathrm{pH}$ is a vital aspect during $F$. verticillioides growth and fumonisin production. Under alkaline kernel conditions, fumonisin production is suppressed (Picot et al., 2011). In our study, maize cultivars in Vaalharts, had significantly more fungal and fumonisin contamination and lower grain $\mathrm{pH}$ as compared to Potchefstroom. F. verticillioides growth is associated with higher $\mathrm{pH}$ and $\mathrm{C} / \mathrm{N}$ during the earlier stages of kernel development, whereas more acidic and lower $\mathrm{C} / \mathrm{N}$ conditions is associated with fumonisin accumulation (Duncan and Howard, 2010; Jiménez et al., 2003). Within this study FER severity, fumonisin contamination and fungal target DNA levels were all negatively associated with $\mathrm{pH}$ and $\mathrm{C} / \mathrm{N}$ because infection indicators were assessed in mature maize kernels.

The role of phenolic acids in the defence against $F$. verticillioides was unclear in this study. In a study by Ferrochio et al. (2013), low levels of ferulic acid were not associated with plant resistance. It was further suggested that for significant reduction of FER and fumonisin contamination to be achieved, an external application of ferulic acid should be applied (Ferrochio et al., 2013). The results in this study, however, indicate no direct link between phenolic acid quantity and resistance to $F$. verticillioides or fumonisin accumulation in mature maize kernels. Phenolic compounds are not induced to inhibit F. verticillioides growth or fumonisin contamination in mature maize kernels (Cassiem, 2018). The kernel moisture content ranged from 11.6-12.6\% for grain evaluated in Potchefstroom and from 11.9-13.5\% for grain evaluated in Vaalharts. Other physico-chemical properties could also regulate fungal and fumonisin contamination in the grain, such as sugar and starch quantity, and could also be evaluated in further studies.

Structural characteristics and infection indicators, whether evaluated as a group or as individual characteristics, did not correlate. This could be due to the artificial inoculation employed that breeched certain structural barriers such as silk length and husk coverage. Nonetheless, there was also no strong correlation between infection indicators of naturally infected samples with structural characteristics. These results suggest that physical features are not sufficient indicators of resistance to FER/fumonisin accumulation. The importance of structural barriers can be further investigated using other inoculation techniques as the inoculation method used in this study breached certain factors such as the husk leaves.

Commercial cultivars in this study showed varying degrees of resistance to FER and fumonisin accumulation. This was especially evident in Vaalharts where there was significant fungal and fumonisin contamination. FER and fumonisin accumulation occur most frequently in, dry conditions (Cao et al., 2014). Environmental conditions favoured disease development and fumonisin production in Vaalharts, as seen with the high levels of infection indicators in certain cultivars. The infection-indicator data in Vaalharts, therefore, suggest that cultivars 1, 2 and 9 are highly tolerant to $F$. verticillioides colonisation and fumonisin accumulation. All three of these cultivars are genetically modified (GM) cultivars. Conversely, cultivars 5 (non-GM), 10 (GM) and 13 (non-GM) are considered as highly susceptible cultivars. This supports findings that commercial cultivars in South Africa display varying degrees of resistance to FER and fumonisin accumulation (Janse van Rensburg et al., 2015).

The water-inoculated grain samples were more contaminated with fumonisins than the F. verticillioidesinoculated samples in the cultivar trial in Vaalharts. The response of cultivars was, however, consistent between the two plots, further supporting the resistance status of the aforementioned cultivars. Field conditions present a variety of factors that could have contributed to this occurrence. The significant genotype by environment effect observed in this study can be ascribed to inherent differences in meteorological conditions at the localities. The maximum temperature and relative humidity at Vaalharts, during the maize-growing season (December to June) is generally higher compared to Potchefstroom (Rose et al., 2016; 2017; Small et al., 2012) providing ideal conditions for fumonisin contamination. In general, 
Vaalharts also has a slightly higher rainfall during April and May, when the grain is drying; and combined with high relative humidity due to irrigation further enhances conditions for fumonisin production. Naturally occurring fumonisin-producing isolates may also have been present and established better under the prevailing conditions compared to the isolate used for inoculation. Other sources of inoculum such as from seed, soil or airborne inoculum could also have contributed to the increased fumonisin levels in naturally infected grain (Munkvold, 2003a). F. verticillioides is the most abundant fumonisin-producing species in South Africa with different isolates possessing highly variable toxigenic potential and generally similar virulence (Schoeman et al., 2018). Although this study showed strong correlations between FER symptoms, fungal growth and fumonisin contamination, certain isolates could be present in very low quantities, proving symptomless yet having a very high toxigenic potential (Miedaner et al., 2010; Schoeman et al., 2018).

In conclusion, the evaluation of physical, biochemical and genetic characteristics, revealed key associations with traditional infection indicators. The genetic response of maize genotypes to $F$. verticillioides infection was paramount for resistance to FER and fumonisin contamination. Furthermore, conditions within the kernel microenvironment such as $\mathrm{pH}$ and $\mathrm{C} / \mathrm{N}$ ratio could serve as indicators of potential resistance. The results from this study, therefore, provide breeders with additional tools for more efficient selection of resistant material. Multi-site, multi-year evaluation of the cultivars used in this study is warranted to determine the stability of their response to $F$. verticillioides infection. Finally, the expression of defence-related genes not only provided an indication of potential resistance but also provided more evidence for the molecular mechanisms governing resistance to $F$. verticillioides.

\section{Acknowledgements}

South African Maize Trust (MTM15-05) and National Research Foundation (Thuthuka) Grant number TTK150706123304 are acknowledged for funding; Agriculutral Research Council - Grain Crops (ARC-GC) is acknowledged for support with field trials; ARC-SCW are acknowledged for the climate data provided and Marieta van der Rijst (ARC-infrutec) for assistance with data analyses. We would like to thank Dr Paul Williams and Judy Psarrakis (Stellenbosch University, Food Science Department) for assistance with NIR-spectroscopy, the Central Analytical Facility (Stellenbosch University) for support with mycotoxin and phenolic acid analysis and the Department of Plant Pathology at Stellenbosch University.

\section{Conflict of interest}

The authors declare no conflict of interest.

\section{References}

Bacon, C.W. and Hinton, D.M., 1994. Symptomless endophytic conlonsation of maize by Fusarium moniliforme. Canadian Journal of Botany 74: 1195-1202.

Bacon, C.W., Glenn, A.E. and Yates, I.E., 2008. Fusarium verticillioides: managing the endophytic association with maize for reduced fumonisins accumulation. Toxin Reviews 27: 411-446.

Bacon, C.W., Yates, I.E., Hinton, D.M. and Meredith, F., 2001. Biological control of Fusarium moniliforme in maize. Environmental Health Perspectives 109: 325-332.

Beekrum, S., Govinden, R., Padayachee, T. and Odhav, B., 2003. Naturally occurring phenols: a detoxification strategy for fumonisin $\mathrm{B}_{1}$. Food Additives and Contaminants 20: 490-493. https://doi. org/10.1080/0265203031000098678

Booth, C., 1971. The genus Fusarium. Commonwealth mycological institute. Kew, Surrey, UK, 237 pp.

Boutigny, A.L., Beukes, I., Small, I., Zühlke, S., Spiteller, M., Janse van Rensburg, B., Flett, B. and Viljoen, A., 2012. Quantitative detection of Fusarium pathogens and their mycotoxins in South African maize. Plant Pathology 61: 522-531.

Boutigny, A.L., Richard-Forget, F. and Barreau, C., 2008. Natural mechanisms for cereal resistance to the accumulation of Fusarium trichothecenes. European Journal of Plant Pathology 121: 411-423.

Breen, S., Williams, S.J., Outram, M., Kobe, B. and Solomon, P.S., 2017. Emerging insights into the functions of pathogenesis-related protein 1. Trends in Plant Science 22: 871-879.

Bustin, S.A., Benes, V., Garson, J.A., Hellemans, J., Huggett, J., Kubista, M., Mueller, R., Nolan, T., Pfaffl, M.W., Shipley, G.L., Vandesompele, J. and Wittwer, C.T., 2009. The MIQE guidelines: minimum information for publication of quantitative real-time PCR experiments. Clinical Chemistry 55: 611-622.

Cao, A., Santiago, R., Ramos, A.J., Souto, X.C., Aquin, O., Malvar, R.A. and Butron, A., 2014. Critical environmental and genotypic factors for Fusarium verticillioides infection, fungal growth and fumonisin contamination in maize grown in north-western Spain. International Journal of Food Microbiology 177: 63-71.

Cassiem, A., 2018. Effect of phenolic compounds on maize ear rot pathogens and associated mycotoxins. MSc-thesis, Stellenbosch University, Stellenbosch, South Africa.

Downey, G., Byrne, S. and Dwyer, E., 1986. Wheat trading in the republic of Ireland: the utility of a hardness index derived by near infrared reflectance spectroscopy. Journal of the Science of Food and Agriculture 37: 762-766.

Duncan, K.E. and Howard, R.J., 2010. Biology of maize kernel infection by Fusarium verticillioides. Molecular Plant-Microbe Interactions 23: 6-16

Ferrochio, L., Cendoya, E., Farnochi, M.C., Massad, W. and Ramirez, M.L., 2013. Evaluation of ability of ferulic acid to control growth and fumonisin production of Fusarium verticillioides and Fusarium proliferatum on maize based media. International Journal of Food Microbiology 167: 215-220. 
Flaherty, J.E., Pirttilä, A.M., Bluhm, B.H. and Woloshuk, C.P., 2003. PAC1, a pH-regulatory gene from Fusarium verticillioides. Applied and Environmental Microbiology 69: 5222-5227.

Flett, B.C., McLaren, N.W. and Wehner, F.C., 1998. Incidence of ear rot pathogens under alternating corn tillage practices. Plant Disease 82: 781-784.

Foley, D.C., 1962. Systemic infection of corn by Fusarium moniliforme. Phytopathology 52: 870-872.

Fox, G. and Manley, M., 2009. Hardness methods for testing maize kernels. Journal of Agricultural and Food Chemistry 57: 5647-5657.

Gelderblom, W.C.A., Jaskiewicz, K., Marasas, W.F.O., Thiel, P.G., Horak, R.M., Vleggaar, R. and Krick, N.P.J., 1988. Fumonisinsnovel mycotoxins with cancer-promoting activity produced by Fusarium moniliforme. Applied and Environmental Microbiology 54: 1806-1811.

Gerber, B.J., 2010. Yield response of Fusarium infected maize seed treated with biological control agent formulations. MSc-thesis, University of South Africa, Pretoria, South Africa.

Guelpa, A., Bevilacqua, M., Marini, F., O’Kennedy, K., Geladi, P. and Manley, M., 2015. Application of Rapid Visco Analyser (RVA) viscograms and chemometrics for maize hardness characterisation. Food Chemistry 173: 1220-1227.

Janse van Rensburg, B., Flett, B.C., McLaren, N.W. and McDonald, A.H., 2011. Sampling variation in the quantification of fumonisins in maize samples. South African Journal of Plant and Soil 28: 90-96.

Janse van Rensburg, B., McLaren, N.W., Flett, B.C. and Schoeman, A., 2015. Fumonisin producing Fusarium spp. and fumonisin contamination in commercial South African maize. European Journal of Plant Pathology 141: 491-504.

Jiménez, M., Mateo, J.J., Hinojo, M.J. and Mateo, R., 2003. Sugars and amino acids as factors affecting the synthesis of fumonisins in liquid cultures by isolates of the Gibberella fujikuroi complex. International Journal of Food Microbiology 89: 185-193.

Jurado, M., Marín, P., Magan, N. and González-Jaén, M.T., 2008. Relationship between solute and matric potential stress, temperature, growth, and FUM1 gene expression in two Fusarium verticillioides strains from Spain. Applied and Environmental Microbiology 74: 2032-2036.

Keller, S.E., Sullivan, T.M. and Chirtel, S., 1997. Factors affecting the growth of Fusarium proliferatum and the production of fumonisin $\mathrm{B}_{1}$ : oxygen and $\mathrm{pH}$. Journal of Industrial Microbiology and Biotechnology 19: 305-309.

Kriek, N.P.J., Kellerman, T.S. and Marasas, W.F.O., 1981. A comparative study of the toxicity of Fusarium verticillioides (=F. moniliforme) to horses, primates, pigs, sheep, and rats. Onderstepoort Journal of Veterinary Research 48: 129-131.

Lanubile, A., Ferrarini, A., Maschietto, V., Delledonne, M., Marocco, A. and Bellin, D., 2014. Functional genomic analysis of constitutive and inducible defence responses to Fusarium verticillioides infection in maize genotypes with contrasting ear rot resistance. BMC Genomics 15: 1-16.

Lanubile, A., Luca, P. and Adriano, M., 2010. Differential gene expression in kernels and silks of maize lines with contrasting levels of ear rot resistance after Fusarium verticillioides infection. Journal of Plant Physiology 167: 1398-1406.
Lanubile, A., Maschietto, V., Borrelli, V.M., Stagnati, L., Logrieco, A.F. and Marocco, A., 2017. Molecular basis of resistance to Fusarium ear rot in maize. Frontiers in Plant Science 8: 1774.

Livak, K.J. and Schmittgen, T.D., 2001. Analysis of relative gene expression data using real-time quantitative PCR and the $2^{-\triangle \Delta C T}$ method. Methods 25: 402-408.

Mabuza, L.M., Janse van Rensburg, B., Flett, B.C. and Rose, L.J., 2018. Accumulation of toxigenic Fusarium species and Stenocarpella maydis in maize grain grown under different cropping systems. European Journal of Plant Pathology 150: 1-12.

Maiorano, A., Reyneri, A., Sacco, D., Magni, A. and Ramponi, C., 2009. A dynamic risk assessment model (FUMAgrain) of fumonisin synthesis by Fusarium verticillioides in maize grain in Italy. Crop Protection 28: 243-256.

Marasas, W.F., Riley, R.T., Hendricks, K.A., Stevens, V.L., Sadler, T.W., Gelineau-Van Waes, J., Missmer, S.A., Cabrera, J., Torres, O., Gelderblom, W.C. and Allegood, J., 2004. Fumonisins disrupt sphingolipid metabolism, folate transport, and neural tube development in embryo culture and in vivo: a potential risk factor for human neural tube defects among populations consuming fumonisin-contaminated maize. Journal of Nutrition 134: 711-716.

Marasas, W.F.O., Wehner, F.C., Van Rensburg, S.J. and Van Schalkwyk, D.J., 1981. Mycoflora of corn produced in human oesophageal cancer areas in Transkei, southern Africa. Phytopathology 71: 792-796.

Marín, S., Magan, N., Ramos, A.J. and Sanchis, V., 2004. Fumonisinproducing strains of Fusarium: a review of their ecophysiology. Journal of Food Protection 67: 1792-1805.

Maschietto, V., Colombi, C., Pirona, R., Pea, G., Strozzi, F., Marocco, A., Rossini, L. and Lanubile, A., 2017. QTL mapping and candidate genes for resistance to Fusarium ear rot and fumonisin contamination in maize. BMC Plant Biology 17: 1-21.

Maschietto, V., Lanubile, A., De Leonardis, S., Marocco, A. and Paciolla, C., 2016. Constitutive expression of pathogenesis-related proteins and antioxidant enzyme activities triggers maize resistance towards Fusarium verticillioides. Journal of Plant Physiology 200: 53-61.

Mesterházy, Á., Lemmens, M. and Reid, L.M., 2012. Breeding for resistance to ear rots caused by Fusarium spp. in maize - a review. Plant Breeding 131: 1-19.

Miedaner, T., Bolduan, C. and Melchinger, A.E., 2010. Aggressiveness and mycotoxin production of eight isolates each of Fusarium graminearum and Fusarium verticillioides for ear rot on susceptible and resistant early maize inbred lines. European Journal of Plant Pathology 127: 113-123.

Munkvold, G.P., 2003a. Epidemiology of Fusarium diseases and their mycotoxins in maize ears. European Journal of Plant Pathology 109: 705-713.

Munkvold, G.P., 2003b. Cultural and genetic approaches to managing mycotoxins in maize. Annual Review of Phytopathology 41: 99-116.

Munkvold, G.P., 2003c. Mycotoxins in corn-occurrence, impact, and management. Corn: Chemistry and Technology 2: 811-881.

Nicolaisen, M., Suproniene, S., Nielsen, L.K., Lazzaro, I., Spliid, H.N. and Justesen, A.F., 2009. Real-time PCR for quantification of eleven individual Fusarium species in cereals. Journal of Microbiological Methods 76: 234-240. 
Parsons, M.W. and Munkvold, G.P., 2010. Associations of planting date, drought stress, and insects with Fusarium ear rot and fumonisin $\mathrm{B}_{1}$ contamination in California maize. Food Additives and Contaminants Part A 27: 591-607.

Pereira, P., Nesci, A. and Etcheverry, M., 2007. Effects of biocontrol agents on Fusarium verticillioides count and fumonisin content in the maize agroecosystem: impact on rhizospheric bacterial and fungal groups. Biological Control 42: 281-287.

Pérez-Brito, D., Jeffers, D., González-de-León, D., Khairallah, M., Cortés-Cruz, M., Velázquez-Cardelas, G., Azpíroz-Rivero, S. and Srinivasan, G., 2001. QTL mapping of Fusarium moniliforme ear rot resistance in highland maize. México Agrociencia 35: 181-196.

Picot, A., Barreau, C., Pinson-Gadais, L., Caron, D., Lannou, C. and Richard-Forget, F., 2010. Factors of the Fusarium verticillioidesmaize environment modulating fumonisin production. Critical Reviews in Microbiology 36: 221-231.

Picot, A., Barreau, C., Pinson-Gadais, L., Piraux, F., Caron, D., Lannou, C. and Richard-Forget, F., 2011. The dent stage of maize kernels is the most conducive for fumonisin biosynthesis under field conditions. Applied and Environmental Microbiology 77: 8382-8390.

Ponts, N., Pinson-Gadais, L., Boutigny, A.L., Barreau, C. and RichardForget, F., 2011. Cinnamic-derived acids significantly affect Fusarium graminearum growth and in vitro synthesis of type B trichothecenes. Phytopathology 101: 929-934.

Presello, D.A., Botta, G., Iglesias, J. and Eyhérabide, G.H., 2008. Effect of disease severity on yield and grain fumonisin concentration of maize hybrids inoculated with Fusarium verticillioides. Crop Protection 27: 572-576.

Reid, L.M., Bolton, A.T., Hamilton, R.I., Woldemariam, T. and Mather, D.E., 1992. Effect of silk age on resistance of maize to Fusarium graminearum. Canadian Journal of Plant Pathology 14: 293-298.

Reid, L.M., Nicol, R.W., Ouellet, T., Savard, M., Miller, J.D., Young, J.C., Stewart, D.W. and Schaafsma, A.W., 1999. Interaction of Fusarium graminearum and F. moniliforme in maize ears: disease progress, fungal biomass, and mycotoxin accumulation. Phytopathology 89: 1028-1037.

Rose, L.J., Mouton, M., Beukes, I., Flett, B.C., Van der Vyver, C. and Viljoen, A., 2016. Multi-environmental evaluation of maize inbred lines for resistance to Fusarium ear rot and fumonisins. Plant Disease 100: 2134-2144.

Rose, L.J., Okoth, S., Beukes, I., Ouko, A., Mouton, M., Flett, B.C., Makumbi, D. and Viljoen, A., 2017. Determining resistance to Fusarium verticillioides and fumonisin accumulation in African maize inbred lines resistant to Aspergillus flavus and aflatoxins. Euphytica 213: 93. https://doi.org/10.1007/s10681-017-1883-7

Salinas-Moreno, Y., García-Salinas, C., Ramírez-Díaz, J.L. and Alemánde la Torre, I., 2017. Phenolic compounds in maize grains and its nixtamalized products. In: Soto-Hernández, M. (ed.) Phenolic compounds-natural sources, importance and applications. InTech, London, UK, chapter 9. https://doi.org/10.5772/66893
Sampietro, D.A., Fauguel, C.M., Vattuone, M.A., Presello, D.A. and Catalán, C.A.N., 2013. Phenylpropanoids from maize pericarp: resistance factors to kernel infection and fumonisin accumulation by Fusarium verticillioides. European Journal of Plant Pathology 135: 105-113.

Sampietro, D.A., Marín, P., Iglesias, J., Presello, D.A., Vattuone, M.A., Catalán, C.A.N. and Jaen, M.G., 2010. A molecular based strategy for rapid diagnosis of toxigenic Fusarium species associated to cereal grains from Argentina. Fungal Biology 114: 74-81.

Schoeman, A., Flett, B.C., Janse van Rensburg, B., Ncube, E. and Viljoen, A., 2018. Pathogenicity and toxigenicity of Fusarium verticillioides isolates collected from maize roots, stems and ears in South Africa. European Journal of Plant Pathology 152: 677-689.

Shim, W.B., Flaherty, J.E. and Woloshuk, C.P., 2003. Comparison of fumonisin $B_{1}$ biosynthesis in maize germ and degermed kernels by Fusarium verticillioides. Journal of Food Protection 66: 2116-2122. Sinha, M., Singh, R.P., Kushwaha, G.S., Iqbal, N., Singh, A., Kaushik, S., Kaur, P., Sharma, S. and Singh, T.P., 2014. Current overview of allergens of plant pathogenesis related protein families. Scientific World Journal 2014: 543195.

Small, I.M., Flett, B.C., Marasas, W.F.O, McLeod, A., Stander, M.A. and Viljoen, A., 2012. Resistance in maize inbred lines to Fusarium verticillioides and Fumonisin accumulation in South Africa. Plant Disease 96: 881-888.

Van Zyl, K., 2015. Resistance in maize to infection and toxin production by Fusarium verticillioides. MSc-thesis, Stellenbosch University, Stellenbosch, South Africa.

Van Zyl, K., 2018. Genetics of fumonisin biosynthesis and resistance to Fusarium verticillioides in maize. PhD-thesis, Stellenbosch University, Stellenbosch, South Africa.

Wang, G., Wang, G., Zhang, X., Wang, F. and Song, R., 2011. Isolation of high-quality RNA form cereal seeds containing high levels of starch. Phytochemical Analysis 23: 159-163.

Warfield, C.Y. and Davis, R.M., 1996. Importance of husk covering on the susceptibility of corn hybrids to Fusarium ear rot. Plant Disease 80: 208-210.

Warfield, C.Y. and Gilchrist, D.G., 1999. Influence of kernel age on fumonisin $\mathrm{B}_{1}$ produced in maize by Fusarium moniliforme. Applied Environmental Microbiology 65: 2853-2856.

Wicklow, D.T., Roth, S., Deyrup, S.T. and Gloer, J.B., 2005. A protective endophyte of maize: Acremonium zeae antibiotics inhibitory to Aspergillusflavus and Fusarium verticillioides. Mycological Research 109: 610-618.

Zabka, M. and Pavela, R., 2013. Antifungal efficacy of some natural phenolic compounds against significant pathogenic and toxinogenic filamentous fungi. Chemosphere 93: 1051-1056. 
